\title{
Audiology and Familial Adenomatous Polyposis: do you hear what I hear?
}

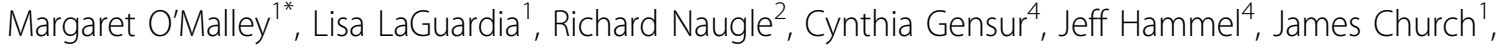 \\ Carol Burke ${ }^{3}$ \\ From 13th Annual Meeting of the Collaborative Group of the Americas on Inherited Colorectal Cancer \\ Honolulu, Hawaii, USA. 16-17 October 2009
}

\section{Background}

The APC protein has an important role in maintaining function of microtubules in the ear which playa significant part in the mechanism of hearing. Preliminary data suggests that the APC protein is associated with an increased incidence of abnormal hearing which may affect intellectual function. We sought to assess the hearing among patients with FAP (Familial Adenomatous Polyposis).

\section{Methods}

Patients with FAP were recruited for an IRB (Institutional Review Board) approved study assessing hearing and intelligence. Hearing was tested by pure tone air conduction audiometry, less than or equal to $30 \mathrm{db}$ at $3 / 4$ of the following frequencies $(500 \mathrm{~Hz}, 1000 \mathrm{~Hz}$, $2000 \mathrm{~Hz}$ and $4000 \mathrm{~Hz}$ ). Subjects were then administered the Kaufman Brief Intelligence Test (KBIT-2). We then analyzed the proportion of individuals with an abnormal audiometry as compared to age and gender adjusted normalized hearing standards.

\section{Results}

44 patients were recruited from 42 families. Subjects included 22 men with a mean age of 42 years. When compared to normalized hearing standards, 19 (43.2\%) of the 44 patients failed to meet the standard normal range. Audiologic abnormalities showed unilateral hearing impairment was documented in 6 patients, bilateral impairment in 13 . Of these patients $63 \%$ were impaired at a single frequency; the other $37 \%$ were at multiple frequencies. $59 \%$ of patients showed right hearing impairment with the highest deficit (35\%) at $2000 \mathrm{~Hz}$. $71 \%$ of patients had left sided impairment with the greatest number (32\%) at $4000 \mathrm{~Hz}$.

\section{Conclusion}

A large subset of our sample of FAP patients (43.2\%) had abnormal audiologic results when compared to the normalized standard. Differences in IQ scores for patients with and without audiologic abnormalities are not statistically significant, suggesting that these results do not reflect an association between hearing and intellectual functioning in our sample.

\section{Author details}

'Sanford R. Weiss, M.D. Center for Hereditary Colorectal Neoplasia, Department of Colorectal Surgery, Cleveland Clinic, Cleveland, Ohio 44195, USA. ${ }^{2}$ Sanford R. Weiss, M.D. Center for Hereditary Colorectal Neoplasia, Department of Psychiatry and Psychology, Cleveland Clinic, Cleveland, Ohio 44195, USA. ${ }^{3}$ Sanford R. Weiss, M.D. Center for Hereditary Colorectal Neoplasia, Department of Gastroenterology, Cleveland Clinic, Cleveland, Ohio 44195, USA. ${ }^{4}$ Sanford R. Weiss, M.D. Center for Hereditary Colorectal Neoplasia, Department of Audiology, Cleveland Clinic, Cleveland, Ohio 44195, USA

Published: 25 May 2010

doi:10.1186/1897-4287-8-S1-P14

Cite this article as: O'Malley et al.: Audiology and Familial Adenomatous Polyposis: do you hear what I hear? Hereditary Cancer in Clinical Practice 2010 8(Suppl 1):P14.

\footnotetext{
* Correspondence: omallem@ccf.org

'Sanford R. Weiss, M.D. Center for Hereditary Colorectal Neoplasia,

Department of Colorectal Surgery, Cleveland Clinic, Cleveland, Ohio 44195,
} USA 